\title{
Melanonychia and Blue lunulae with the Multikinase Inhibitor Sorafenib
}

\section{Osvaldo Correia ${ }^{1,2 *}$, Ana Filipa Duarte ${ }^{1}$, José Dinis Silva ${ }^{3}$ and Eckart Haneke ${ }^{1,4}$}

${ }^{1}$ Centro Dermatologia Epidermis, Instituto CUF, Porto, Portugal

${ }^{2}$ Faculty of Medicine, University of Porto, Portugal

${ }^{3}$ Serviço de Oncologia Médica do Instituto Português de Oncologia, Centro do Porto, Portugal

${ }^{4}$ Department of Dermatology, Inselspital, University of Bern, Switzerland and Dermaticum, Freiburg, Germany

\section{Introduction}

Molecular targeted therapy with monoclonal antibodies and low molecular weight inhibitors have gained increasing importance particularly in the treatment of malignant tumors. Sorafenib (Nexavar) is an oral multikinase inhibitor that blocks tumor cell proliferation and angiogenesis and is used for the treatment of advanced renal cell carcinoma, hepatocellular carcinoma, and other solid tumors including metastatic differentiated thyroid cancer, at a starting dose of $400 \mathrm{mg}$ twice daily [1-4]. The most common adverse effects are fatigue, diarrhea, and various other dermatologic side effects [1]. Recently, a meta-analysis of dermatological toxicities associated with sorafenib has been published, [5] and a hand-foot-skin reactions (HFSR) was most often found, but also rash/desquamation, alopecia, pruritus and dry skin. Nail involvement has been reported, in particular sub-ungual splinter hemorrhages [6]. We describe a patient with longitudinal melanonychia and blue lunulae that developed during sorafenib therapy of metastatic thyroid carcinoma.

Keywords: Melanonychia; Sorafenib

\section{Case Report}

A 51-year-old woman had a diagnosis of well differentiated papillar thyroid carcinoma, stage IV, with multiple gross bone metastases. She had undergone total thyroidectomy subsequently to several courses of radioiodine $\left(\mathrm{I}^{131}\right)$. Four years later, the disease progressed with new bone lesions and pulmonary metastasis. The disease was classified as resistant to radioiodine treatment. Orthopedic surgery of the spine was performed twice (D10-D11 and L-L4). Other therapeutic options were evaluated and the patient began a treatment with sorafenib, $400 \mathrm{mg}$ twice daily.

After four weeks of continuous treatment, she developed diffuse pruritus and facial erythema with dysesthesia and noticed intensive hair loss. On physical examination, we found longitudinal melanonychia of the left great toe nail (Figure 1) and a bluish discoloration of the lunulae was evident in both great toenails (Figure 2). The patient denied to have had similar nail alterations before and any recent medication changes.

\section{Discussion}

Several cutaneous side effects have been reported with sorafenib [1,5-10]. A meta-analysis to determine the type, incidence and risks of dermatological toxicities associated with sorafenib treatment of advanced solid tumors, usually at a starting dose of $400 \mathrm{mg}$ twice daily, showed that the most frequent dermatological adverse effects were hand-foot-skin reactions (HFSR) (39.0\%), rash/desquamation (35.4\%), alopecia $(25.5 \%)$, pruritus $(14 \%)$ and dry skin $(14,1 \%)$. The HFSR is clinically distinct from the well-known chemotherapy-induced handfoot syndrome, because it presents as painful symmetrical erythematous and edematous areas on the palms and/or soles commonly associated with paresthesias, but the erythema turns thick with desquamation and sometimes callus-like hyperkeratosis, particularly but not exclusively on pressure areas [7]. No significant correlation between HFSR severity and response to treatment was seen [7].

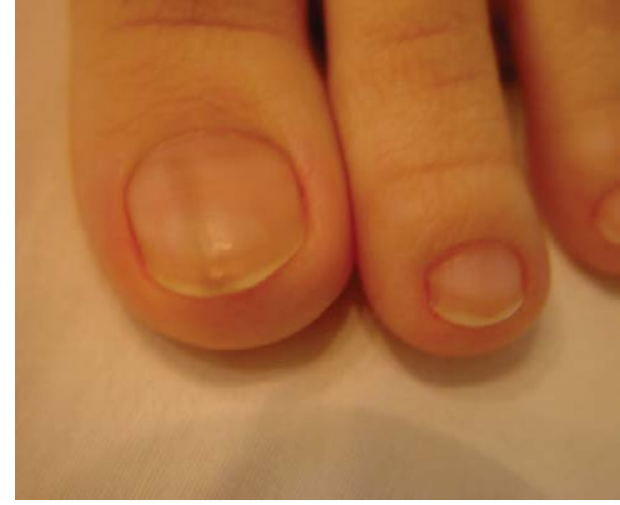

Figure 1: Longitudinal melanonychia.

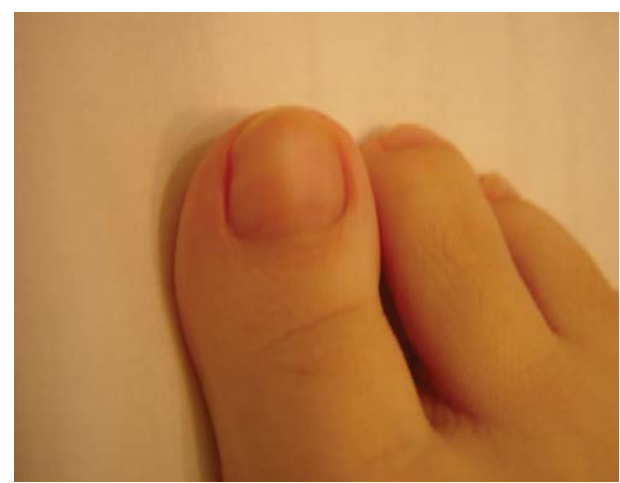

Figure 2: Blue discoloration of the lunula.

Other cutaneous adverse effects include facial/scalp erythema/ dysesthesias, a keratosis pilaris-like eruption and more rarely eruptive keratoacanthomas, nevi, cysts, inflamed actinic and seborrheic keratoses.

Nail involvement has been reported [1,2,5-10], mainly multiple, painless subungual splinter hemorrhages. These hemorrhages usually developed 2 to 4 weeks after the onset of therapy and are probably

*Corresponding author: Osvaldo Correia, Center of Dermatology "Epidermis", CUF Institute, Rua Fonte das Sete Bicas 170, 4460-188 Senhora da Hora - Matosinhos, Portugal, Tel: 0035191 9021091; Fax: 00351220033720 E-mail: epidermis@epidermis.pt

Received May 05, 2015; Accepted June 04, 2015; Published June 15, 2015

Citation: Correia O, Duarte AF, Silva JD, Haneke E. (2015) Melanonychia and Blue lunulae with the Multikinase Inhibitor Sorafenib. J Pharmacovigilance S2: 001. doi:10.4172/2329-6887.S2-001

Copyright: $\odot 2014$ Correia O, et al., This is an open-access article distributed under the terms of the Creative Commons Attribution License, which permits unrestricted use, distribution, and reproduction in any medium, provided the original author and source are credited. 
related to inhibition of vascular endothelial growth factor receptor [6]. Our patient presented with diffuse pruritus, facial erythema with dysesthesia, pronounced effluvium and peculiar nail involvement. Besides a longitudinal melanonychia on the left great toenail, a bluish discoloration of the lunulae was present in both great toenails. To our knowledge, the appearance of blue lunulae has not been reported before with sorafenib.

Skin toxicities of sorafenib are mainly mild or moderate as they usually do not require drug withdrawal [5-10]. Sometimes they require dose modifications and/or treatment interruptions [11]. Increased awareness by dermatologists who work with oncologists, of the diversity, frequency, and treatment of sorafenib-induced cutaneous adverse reactions will be helpful for patients who require long-term therapy with this medication for their cancers.

\section{References}

1. Heidary N, Naik H, Burgin S (2008) Chemotherapeutic agents and the skin: An update. J Am Acad Dermatol 58: 545-570.

2. Eisen T, Sternberg CN, Robert C, Mulders P, Pyle L, et al. (2012) Targeted therapies for renal cell carcinoma: review of adverse event management strategies. J Natl Cancer Inst 104: 93-113.
3. Cabanillas ME, Waguespack SG, Bronstein Y, Williams MD, Feng L, et al. (2010) Treatment with tyrosine kinase inhibitors for patients with differentiated thyroid cancer: the M. D. Anderson experience. J Clin Endocrinol Metab 95: 2588-2595.

4. Busaidy NL, Cabanillas ME (2012) Differentiated thyroid cancer: management of patients with radioiodine nonresponsive disease. J Thyroid Res 2012: 618985.

5. Zhang L, Zhou Q, Ma L, Wu Z, Wang Y (2011) Meta-analysis of dermatological toxicities associated with sorafenib. Clin Exp Dermatol 36: 344-350.

6. Robert C, Faivre S, Raymond E, Armand JP, Escudier B (2005) Subungual splinter hemorrhages: a clinical window to inhibition of vascular endothelial growth factor receptors? Ann Intern Med 143: 313-314.

7. Lee WJ, Lee JL, Chang SE, Lee MW, Kang YK, et al. (2009) Cutaneous adverse effects in patients treated with the multitargeted kinase inhibitors sorafenib and sunitinib. Br J Dermatol 161: 1045-1051.

8. Robert C, Mateus C, Spatz A, Wechsler J, Escudier B (2009) Dermatologic symptoms associated with the multikinase inhibitor sorafenib. J Am Acad Dermatol 60: 299-305

9. Kong HH, Turner ML (2009) Array of cutaneous adverse effects associated with sorafenib. J Am Acad Dermatol 61: 360-361.

10. Autier J, Escudier B, Wechsler J, Spatz A, Robert C (2008) Prospective study of the cutaneous adverse effects of sorafenib, a novel multikinase inhibitor. Arch Dermatol 144: 886-892.

11. Ara M, Pastushenko E (2014) Antiangiogenic agents and the skin: cutaneous adverse effects of sorafenib, sunitinib, and bevacizumab. Actas Dermosifiliogr 105: 900-912.
This article was originally published in a special issue, Medication Errors handled by Editor(s). Dr. Prashansa Agrwal, University of Arizona, USA 